\title{
EFEKTIFITAS PEMBERIAN TEH JAHE UNTUK MENGATASI HIPEREMESIS GRAVIDARUM PADA IBU HAMIL TRIMESTER 1 DI PUSKESMAS KOTA MAKASSAR
}

\section{The effectiveness of giving ginger tea to overcome gravidarum hyperemesis in trimester 1 pregnant women in puskesmas, makassar city}

\author{
Hasnita, Hasnaeni \\ STIKES Nani Hasanuddin Makassar \\ hasnita@stikesnh.ac.id
}

\begin{abstract}
ABSTRAK
Hiperemesis gravidarum adalah muntah yang terjadi sampai umur kehamilan 20 minggu, muntah begitu hebat dimana segala apa yang dimakan dan diminum dimuntahkan sehingga mempengaruhi keadaan umum dan pekerjaan sehari hari, berat badan menurun dehidrasi, dan terdapat aseton dalam urin bukan karena penyakit seperti appendisitis, pielititis, dan sebagainya. Penelitian modern telah membuktikan secara ilmiah berbagai manfaat jahe, antara lain : mencegah mual, karena jahe mampu memblok serotonin yaitu senyawa kimia yang dapat menyebabkan perut berkontraksi, sehingga timbul rasa mual. Hal ini bermanfaat jika diberikan pada ibu hamil karena dapat meringankan hyperemesis yang dialami. Tujuan penelitian ini adalah Untuk mengetahui efek dari pemberian teh jahe pada ibu hamil dengan hiperemesis gravidarum di Puskesmas Kapasa Kota Makassar. Penelitian ini menggunakan desain ekperimental yang bersifat one grup pretest-postest. Penelitian ini dilaksanakan di Wilayah kerja Puskesmas Kapasa Kota Makassar pada bulan Januari sampai Agustus 2020. Populasi dalam penelitian ini adalah ibu hamil trimester 1 dengan jumlah sampel 50 responden. Hasil analisis bivariat menunjukkan ada perbedaan rata-rata frekuensi mual muntah sebelum dan sesudah intervensi teh jahe sebesar 1,04 dengan $p=0,000$.
\end{abstract}

Kata Kunci : Hamil, Hiperemesisi, Jahe

\section{ABSTRACT}

Hyperemesis gravidarum is vomiting that occurs until 20 weeks of gestation, vomiting is so intense that everything eaten and drunk is vomited up, affecting general conditions and daily work, body weight decreases dehydration, and there is acetone in the urine not due to diseases such as appendicitis, pyelititis, etc. Modern research has scientifically proven the various benefits of ginger, including: preventing nausea, because ginger is able to block serotonin, a chemical that causes the stomach to contract, resulting in nausea. This is useful if given to pregnant women because it can relieve hyperemesis experienced. The purpose of this study was to determine the effect of giving ginger tea to pregnant women with hyperemesis gravidarum at Puskesmas Kapasa, Makassar City. This study used an experimental design that was one group pretest-posttest. This research was conducted in the working area of the Kapasa Public Health Center in Makassar City from January to August 2020. The population in this study were pregnant women in the first trimester with a total sample of 50 respondents. The results of the bivariate analysis showed that there was a difference in the average frequency of nausea and vomiting before and after the ginger tea intervention of 1.04 with $p=0.000$.

Keywords: Ginger, Hyperemesisi, Pregnant

\section{PENDAHULUAN}

Hiperemesis gravidarum adalah muntah yang terjadi sampai umur kehamilan 20 minggu, muntah begitu hebat dimana segala apa yang dimakan dan diminum dimuntahkan sehingga mempengaruhi keadaan umum dan pekerjaan sehari -hari, berat badan menurun dehidrasi, dan terdapat aseton dalam urin bukan karena penyakit seperti appendisitis, pielititis,

dan sebagainya(Joseph 2010)

Hyperemesis gravidarum terjadi di seluruh dunia dengan angka kejadian yang beragam, sebanyak $0,3 \%$ dari seluruh kehamilan di Swedia, 0,5\% di California, $0,8 \%$ di Canada, 0,8\% di China, 0,9\% di Norwegia, 2,2\% di Pakistan dan 1,9\% di Turki. Literatur juga menyebutkan bahwa perbandingan insidensi hiperemesis gravidarum secara umum adalah 4:1000 kehamilan (Yasa AR 2012)

Data mengenai Hyperemesis Gravidarum untuk daerah Sulawesi Selatan berdasarkan hasil laporan pada tahun 2016 jumlah ibu hamil sebanyak 2.203 dengan 543 ibu hamil yang mengalami Hyperemesis Gravidarum dan 2 orang meninggal akibat Hyperemesis gravidarum.

Salah satu komplikasi kehamilan yang mempengaruhi status kesehatan ibu dan tumbuh kembang janin adalah Hyperemesis Gravidarum dimana kejadian ini dapat dideteksi dan dicegah pada masa kehamilan, mual dan muntah merupakan gangguan yang paling sering dijumpai pada kehamilan trimester I sekitar 60 - $80 \%$ 
pada primigravida dan 40 - $60 \%$ pada multi gravida (Wiknjosastro 2010)

Penyebab

hyperemesis gravidarum belum di ketahui secara pasti, tidak ada bukti bahwa penyakit ini disebabkan oleh faktor toksis, kelainan biokimia, perubahan-perubahan anatomik yang terjadi pada otak, jantung, hati dan susunan syaraf di sebabkan oleh kekurangan vitamin serta zat-zat lain akibat kelemahan tubuh karena tidak makan dan minum, beberapa faktor predisposisi dan faktor lain yang telah ditemukan adalah sering terjadinya pada primigravida, masuknya vili khorialis dalam sirkulasi maternal dan perubahan metabolisme akibat hamil serta resistensi yang menurun dari pihak ibu terhadap perubahan ini merupakan faktor organik alergi, faktor psikologik, faktor adaptasi dan hormonal(Rukiyah 2010)

Jahe adalah tanaman dengan sejuta khasiat yang telah dikenal sejak lama. Jahe merupakan salah satu rempah penting. Rimpangnya sangat banyak manfaatnya, antara lain sebagai bumbu masak, minuman, serta permen dan juga digunakan dalam ramuan obat tradisianal. Keungulan pertama jahe adalah kandungan minyak atsiri yang mempunyai efek menyegarkan dan memblokir reflek muntah, sedang gingerol dapat melancarkan darah dan saraf-saraf bekerja dengan baik. Hasilnya ketegangan bias dicairkan, kepala jadi segar, mual muntah pun ditekan. Aroha harum jahe dihasilkan oleh minyak arsiri, sedang oleoresisnya menyebabkan rasa pedas yang menghangatkan tubuh dan mengeluarkan keringat.

Beberapa hasil penelitian menunjukkan bahwa jahe merupakan bahan terapi untuk meredakan dan mengurangi rasa mual dan muntah. Selain itu jahe juga efektif dalam mengurangi emesis gravidarum pada ibu hamil trimester pertama kehamilan dan menurunkan mual muntah pada ibu yang multigravida.

Mengingat kasus Hiperemisis Gravidarum dapat menimbulkan komplikasi yang lebih berat dan mempengaruhi status kesehatan ibu dan anak, maka dari itu kami tertarik untuk melakukan penelitian di Puskesmas Kapasa Kota Makassar dengan judul "Efektivitas Pemberian Teh Jahe Untuk Mengatasi Hiperemisis Gravidarum Pada Ibu Hamil Trimester 1",tahun 2020.

\section{METODE}

Metode dalam Penelitian yang digunakan adalah quasi experiment, menggunakan pendekatan "one group pretest - postest design" untuk mengidentifikasi efek mengkomsumsi jahe dalam menurunkan mual dan muntah pada penderita hiperemisis gravidarum. Melakukan perlakuan-perlakuan (mengkomsumsi minuman jahe $2 \mathrm{X} / \mathrm{hari}$ masing-masing sebanyak $125 \mathrm{mg}$ pada waktu 08.00 WITA dan pemberian kedua pada pukul 20.00 WITA) terhadap kelompok perlakuan (penderita Hiperemisi Gravidarum).

Populasi pada penelitian ini adalah semua ibu hamil trimester 1 yang berada di wilayah kerja Puskesmas. Teknik pengambilan sampel yaitu menggunakan purposive sampling, yaitu sebanyak 50 orang berdasarkan kriteria inklusi. Informasi tersebut didapatkan dari buku kunjungan kohort kunjungan ibu hamil di Puskesmas Kapasa Kota Makassar.

\section{HASIL}

\section{Analisis Univariat}

1. Umur

Data responden dengan umur $<20$ tahun yaitu 13 Responden (26\%), umur 20-35 Tahun sebanyak 32 responden $(64 \%)$ dan umur $>35$ tahun sebanyak 5 responden (10\%).

2. Gravida

Data responden dengan Primigravida yaitu 24 responden (48\%), sedangkan Multigravida sebanyak 26 responden $(52 \%)$.

3. Pendidikan

Data responden dengan pendidikan SD yaitu 7 responden (14\%), SMP sebanyak 16 (42\%), SMA sebanyak $18(36 \%)$, dan Perguruan Tinggi sebanyak 9 responden (18\%).

4. Pekerjaan

Data responden yang Bekerja yaitu 24 responden (48\%), sedangkan Tidak Bekerja sebanyak 26 responden $(52 \%)$.

5. Frekuensi Mual dan Muntah Sebelum Pemberian Teh Jahe

Data responden Frekuensi Mual dan Muntah Setelah Pemberian Teh Jahe dengan Emesis Ringan yaitu 36 responden $(72 \%)$, Emesis Sedang sebanyak 14 responden (28\%), dan tidak ada responden yang mengalami Emesis Berat. 
6. Frekuensi Mual dan Muntah Setelah Pemberian Teh Jahe

Data responden Frekuensi Mual dan Muntah Setelah Pemberian Teh Jahe dengan Emesis Ringan yaitu 36 responden (72\%), Emesis Sedang sebanyak 14 responden (28\%), dan tidak ada responden yang mengalami Emesis Berat.

\section{Analisis Bivariat}

Terdapat perbedaan rata-rata frekuensi mual muntah sebelum dan sesudah intervensi teh jahe sebesar 1,04 dengan $p$ value $=0.000$, yang artinya pemberian teh jahe dapat mengurangi frekuensi mual dan muntah pada ibu hamil trimester I di Puskesmas Kapasa Kota Makassar Tahun 2020.

\section{PEMBAHASAN}

Hasil penelitian yang diperoleh menunjukkan ada perbedaan rata-rata frekuensi mual muntah pada ibu hamil trimester 1 sebelum dan sesudah pemberian teh jahe. Hasil analisis bivariat dengan menggunakan Independent Sampel T-test, sebesar 1,04 dengan $p$ value $=0,000$. Sehingga dapat disimpulkan pemberian teh jahe efektif dalam menurunkan frekuensi mual dan muntah pada ibu hamil trimester 1 di Puskesmas Kapasa Kota Makassar Tahun 2020.

Meskipun ada perbedaan yang signifikan namun ternyata masih ada 3 responden $(22,2 \%)$ tetap mengalami emesis sedang. Setelah dilakukan penelusuran pada ketiga responden didapatkan jika ketiga responden tidak meminum teh jahe secara tetatur sesuai dengan instruksi.

Penelitian ini sejalan dengan penelitian yang dilakukan oleh Iluh MI dkk (2017), yang meneliti Efektifitas Pemberian Wedang Jahe Terhadap Frekuensi Mual Dan Muntah Pada Ibu Hamil Trimester I Di Kabupaten Bengkulu Utara Tahun 2017, hasilnya sebelum dan sesudah intervensi wedang jahe sebesar 4,80 dengan $p$ value $=0,000$, yang berarti pemberian wedang jahe efektif dalam mengurangi frekuensi mual dan muntah pada ibu hamil trimester I di Kabupaten Bengkulu Utara tahun 2017 (lluh Ml dkk 2017)

Penelitian ini juga sejalan dengan penelitian oleh Ayu D dkk (2017) dengan penelitian Efektifitas Pemberian Jahe Hangat Dalam Mengurangi Frekuensi Mual
Muntah Pada Ibu Hamil Trimester I. hasilnya Setelah diberikan minuman jahe hangat frekuensi mual muntah pada responden menurun dari 13 kali menjadi 3,8 kali per hari. Sehingga pemberian minuman jahe hangat efektif dalam mengurangi frekuensi mual muntah pada ibu hamil trimester pertama (Ayu D dkk 2017)

Jahe berkhasiat sebagai anti muntah dan dapat digunakan para ibu hamil mengurangi morning sickness. Penelitian menunjukkan bahwa jahe sangat efektif menurunkan metoklopamid senyawa penginduksi mual dan muntah. Jahe putih kecil memiliki kandungan minyak atsirinya lebih besar dari pada jahe gajah, sehingga rasanya lebih pedas, disamping seratnya tinggi dan sering ditemukan dipasaran, sehingga jahe dapat dijadikan sebagai pengobatan alternatif untuk mengatasi emesis gravidarum sebelum menggunakan obat antiemetik. Kandungan wedang jahe aman dari bahan berbahaya karena dapat dibuat sendiri sehingga ibu hamil tidak perlu khawatir akan membahayakan kehamilan dan janinnya (Putri 2017)

Mekanisme jahe memiliki efek langsung dalam saluran pencernaan dengan meningkatkan pergerakan lambung, serta absorbsi racun dan asam. Jahe dipercaya sebagai pemberi perasaan nyaman dalam perut sehingga dapat mengatasi mual muntah karena kandungan minyak Atsiri Zingiberena, Zingiberol, Bisabilena, Kurkuman, Gingerol, Flandrena, vit $A$ dan resin pahit. Kandungan zat-zat tersebut dapat memblok serotonin yaitu suatu neurotransmitter sistem saraf pusat dan sel-sel enterokromafin dalam saluran pencernaan dengan menghambat induksi HCG ke lambung.

\section{KESIMPULAN}

Teh jahe efektif dalam menurunkan frekuensi mual dan muntah pada ibu hamil trimester 1 di Puskesmas Kapasa Kota Makassar Tahun 2020.

\section{SARAN}

1. Hasil penelitian ini diharapkan menjadi referensi dalam menangani mual muntah pada ibu hamil, sehingga penggunaan obat-obat farmakologi sedikit demi sedikit dikurangi.

2. Untuk peneliti selanjutnya diharapkan dapat melajutkan penelitian ini dengan 
melihat dosis yang tepat dalam mengurangi mual muntah pada ibu hamil.

\section{UCAPAN TERIMA KASIH}

Kepada yang terhormat :

1. Menteri Riset, teknologi dan pendidikan tinggi, Bapak Mohammad Nasir yang telah membiayai penelitian ini melalui Hibah Eksternal Skim Penelitian Dosen Pemula (PDP).

2. Ketua STIKES Nani Hasanuddin Makassar bapak Yasir Haskas yang memberikan dukungan motivasi dan materil.

3. Kepala P3M STIKES Nani Hasanuddin Makassar, Ibu Suarnianti yang selalu memberikan motivasi kepada dosen untuk produktif menghasilkan penelitian dan pengabdian pada msyarakat

4. Kepala Puskemas Kapasa yang telah memberi izin melaksanakan penelitian di Puskesmas Kapasa

5. Responden yang bersedia bekerjasama memberikan data dan informasi sehingga penelitian ini dapat terlaksana.

\section{DAFTAR PUSTAKA}

Amalia R dkk. 2020. "Efektifitas Pemberian Rebusan Jahe Terhadap Penurunan Mual dan Muntah pada Ibu Hamil Trimester I di Wilayah Puskesmas Gunung Sari Kabupaten Lombok Barat". Dinamika Kesehatan : Jurnal Kebidanan dan Keperawatan.
Ayu D dkk. 2017. "Efektifitas Pemberian Jahe Hangat Dalam Mengurangi Frekuensi Mual Muntah Pada Ibu Hamil Trimester I." Prosiding Seminar Nasional IKAKESMADA.

lluh Ml dkk. 2017. "Efektifitas Pemberian Wedang Jahe Terhadap Frekuensi Mual Dan Muntah Pada Ibu Hamil Trimester I Di Kabupaten Bengkulu Utara Tahun 2017." 5.

Joseph. 2010. Ginekologi Dan Obsteri (Obsgyn). Yogyakarta: Nuha Medika.

Putri, dkk. 2017. "Efektifitas Pemberian Jahe Hangat Dalam Mengurangi Frekuensi Mual Muntah Pada Ibu Hamil Trimester I." Fakultas IImu Kesehatan Universitas Muhammadiyah Parepare.

Rukiyah, A.Y. 2010. Asuhan Kebidanan 4 Patologi. 4th ed. Jakarta: EGC.

Saswita. Efektifitas Jahe Dalam Mengurangi Emesis Gravidarum pada Ibu Hamil Trimester I. 1, 2013: Jurnal Ners Indonesia, Vol. 2.

Wiknjosastro. 2010. Buku Panduan Praktis Pelayanan Kesehatan Maternal Dan Neonatal. 1st ed. Jakarta: Bina Pustaka.

Yasa AR, Aril Cikal. 2012. "Hubungan Antara Karakteristik Ibu Hamil Dengan Kejadian Hiperemesis Gravidarum Di RSUD Ujungberung." Universitas Islam Bandung Fakultas Kedokteran. 
Tabel 1

Karakteristik Sampel pada penelitian Efektifitas Pemberian Teh Jahe Untuk Mengatasi Hiperemesis Gravidarum Pada Ibu Hamil Trimester 1 Di Puskesmas Kota Makassar

\begin{tabular}{|c|c|c|}
\hline Karakteristik Sampel & $\mathrm{n}$ & $\%$ \\
\hline \multicolumn{3}{|l|}{ Umur } \\
\hline$<20$ Tahun & 13 & 26 \\
\hline 20-35 Tahun & 32 & 64 \\
\hline > 35 Tahun & 5 & 10 \\
\hline \multicolumn{3}{|l|}{ Gravid } \\
\hline Primigravida & 24 & 48 \\
\hline Multigravida & 26 & 52 \\
\hline \multicolumn{3}{|l|}{ Pendidikan } \\
\hline SD & 7 & 14 \\
\hline SMP & 16 & 42 \\
\hline SMA & 18 & 36 \\
\hline PT & 9 & 18 \\
\hline \multicolumn{3}{|l|}{ Pekerjaan } \\
\hline Bekerja & 24 & 48 \\
\hline Tidak Bekerja & 26 & 52 \\
\hline \multirow{2}{*}{\multicolumn{3}{|c|}{$\begin{array}{l}\text { Frekuensi Mual dan Muntah } \\
\text { Sebelum Pemberian Teh Jahe }\end{array}$}} \\
\hline & & 16 \\
\hline Emesis Sedang (7-12) & $\begin{array}{l}0 \\
18\end{array}$ & 36 \\
\hline Emesis Berat (13-15) & 24 & 48 \\
\hline \multicolumn{3}{|c|}{$\begin{array}{l}\text { Frekuensi Mual dan Muntah } \\
\text { Setelah Pemberian Teh Jahe }\end{array}$} \\
\hline Emesis Ringan $(\leq 6)$ & & 72 \\
\hline Emesis Sedang (7-12) & $\begin{array}{l}30 \\
14\end{array}$ & 28 \\
\hline Emesis Berat (13-15) & 0 & 0 \\
\hline
\end{tabular}

Tabel 2

Efektifitas Pemberian Teh Jahe Untuk Mengatasi Hiperemesis Gravidarum Pada Ibu Hamil Trimester 1 Di Puskesmas Kota Makassar

\begin{tabular}{c|c|c|c|c|c|c}
\hline $\begin{array}{c}\text { Interven } \\
\text { si }\end{array}$ & $\mathbf{N}$ & Mean & $\begin{array}{c}\text { Mean } \\
\text { Perbeda } \\
\text { an }\end{array}$ & SD & SE & $\boldsymbol{P}$ value \\
\hline Sebelum & 50 & 2.32 & & 0.7 & 0.1 & \\
\hline Setelah & 50 & 1.28 & & 41 & 05 & \multirow{2}{*}{0.000} \\
\cline { 1 - 3 } & & & 54 & 0.4 & 0.00 & \\
\hline
\end{tabular}

